\title{
AUSTRALIA: THE NUMBERS
}

\section{HIGH-QUALITY PAPERS}

Australian universities have had more physical sciences articles included in the index between 2012 and 2015 than papers in any other field.

\section{PHYSICAL SCIENCES}

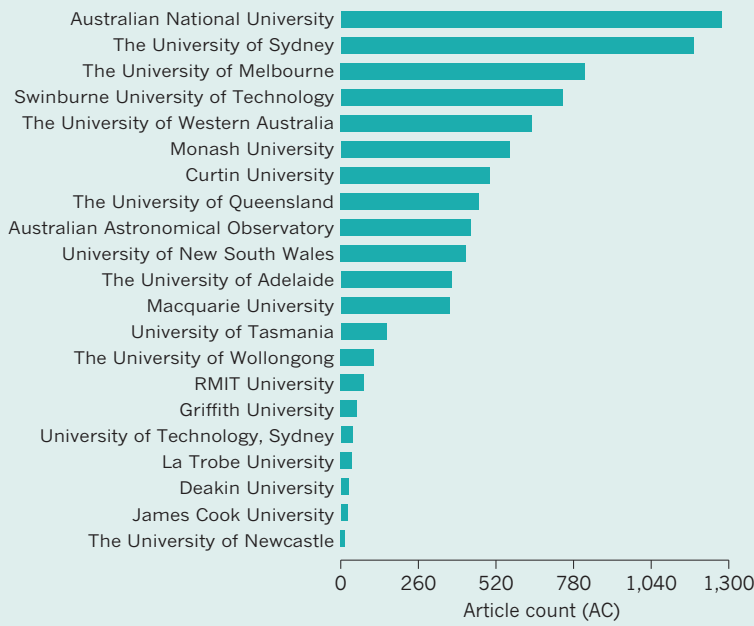

CHEMISTRY

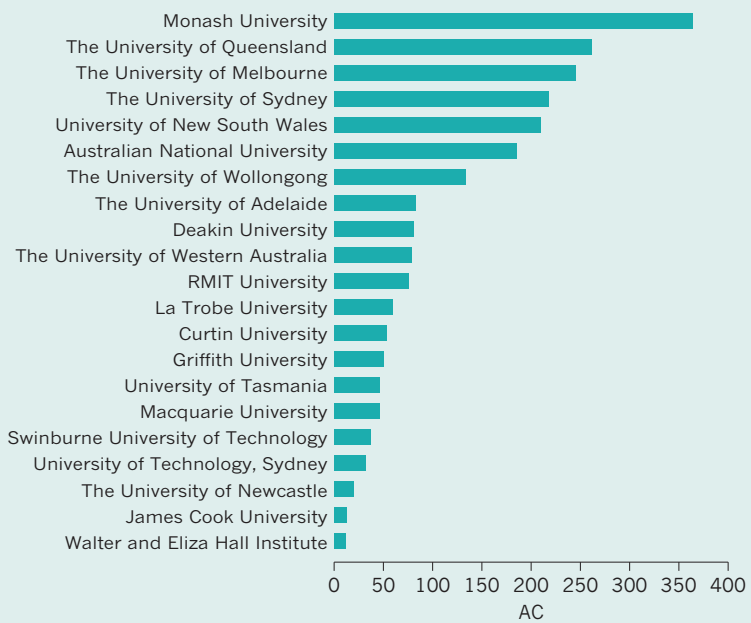

\section{RESEARCH FUNDING}

Australia's top universities were awarded the most money from competitive funding programs between 2011 and 2014.

PHYSICAL

SCIENCES

CHEMISTRY

LIFE SCIENCES

EARTH AND

ENVIRONMENTAL SCIENCES
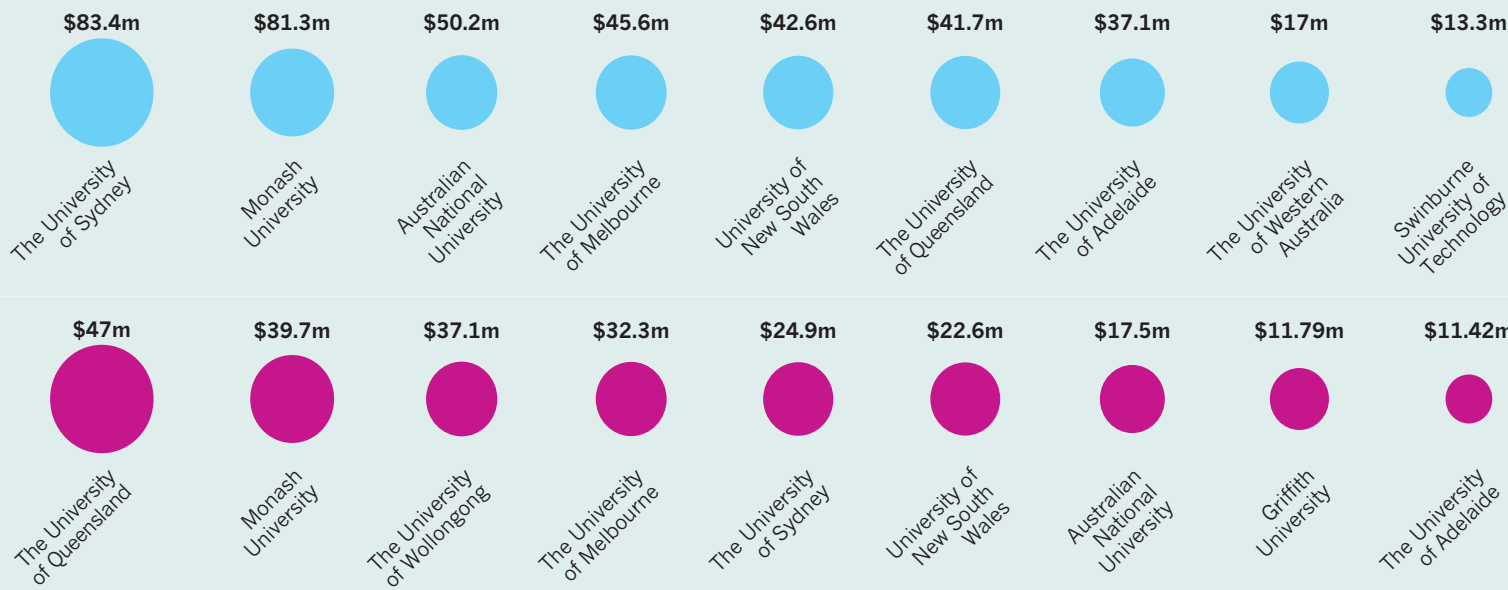

$\$ 32.3 \mathrm{~m}$
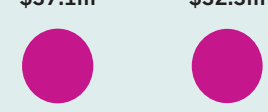

$\$ 24.9 m$
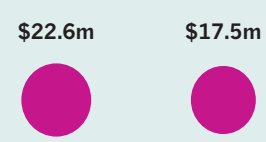

$\$ 11.79 m$

$\$ 11.42 m$
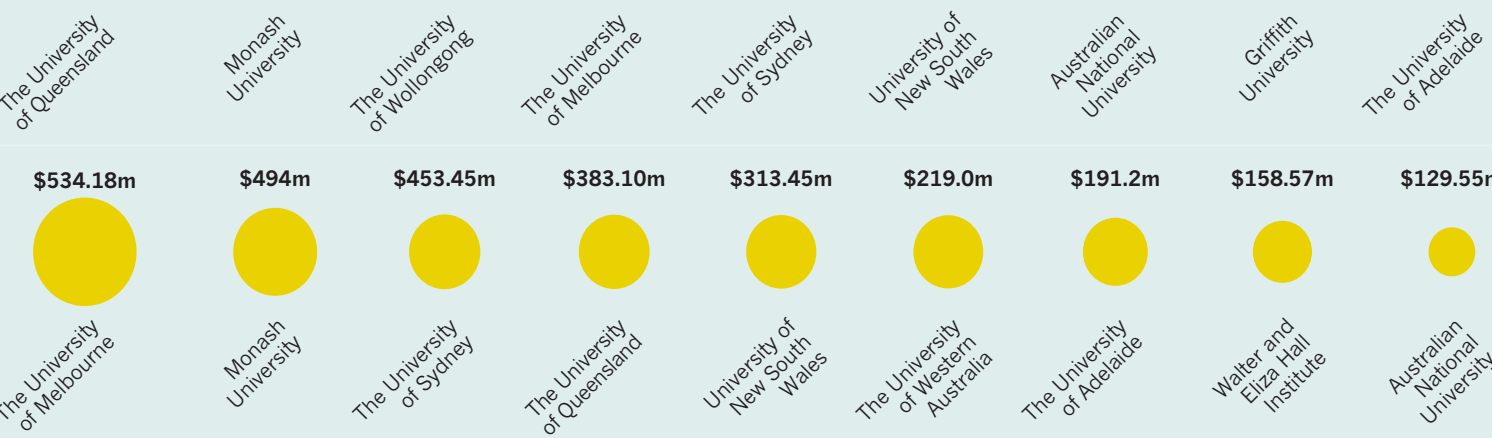

$\$ 494 m$

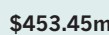

$\$ 383.10 \mathrm{~m}$

$\$ 313.45 \mathrm{~m}$

$\$ 219.0 \mathrm{~m}$

$\$ 191.2 \mathrm{~m}$

$\$ 158.57 m$

$\$ 129.55 m$
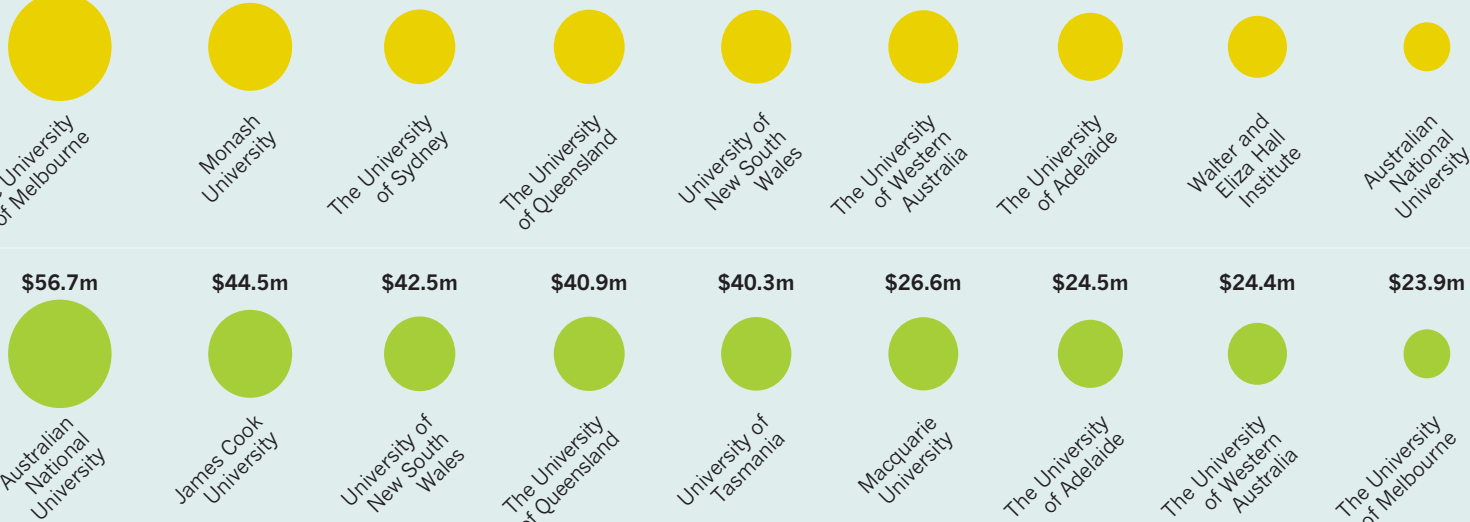

$\$ 40.9 m$

$\$ 40.3 m$

$\$ 26.6 \mathrm{~m}$

$\$ 24.5 \mathrm{~m}$

$\$ 24.4 m$

$\$ 23.9 m$
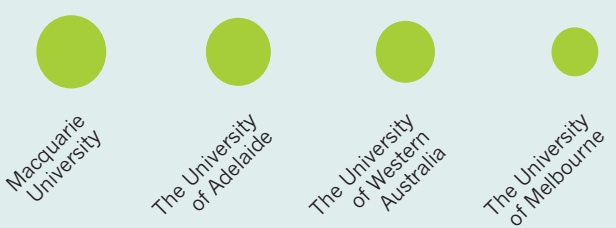


\section{LIFE SCIENCES}

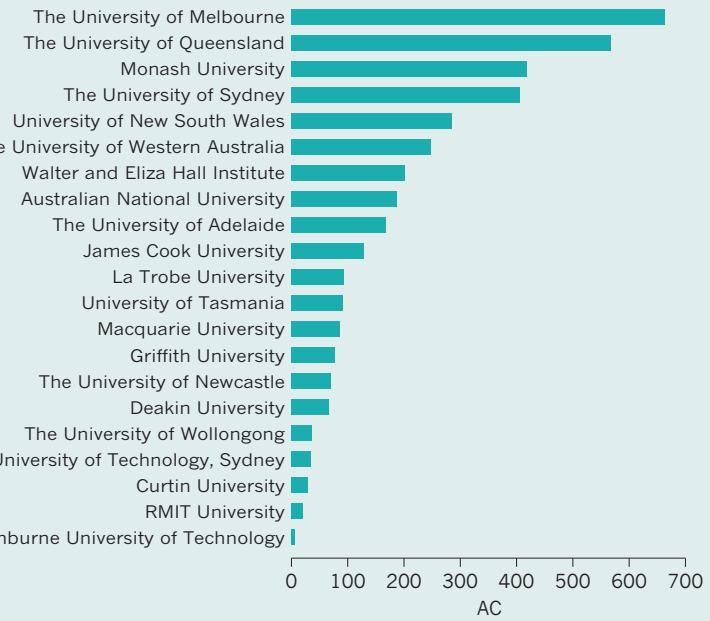

\section{EARTH AND ENVIRONMENTAL SCIENCES}

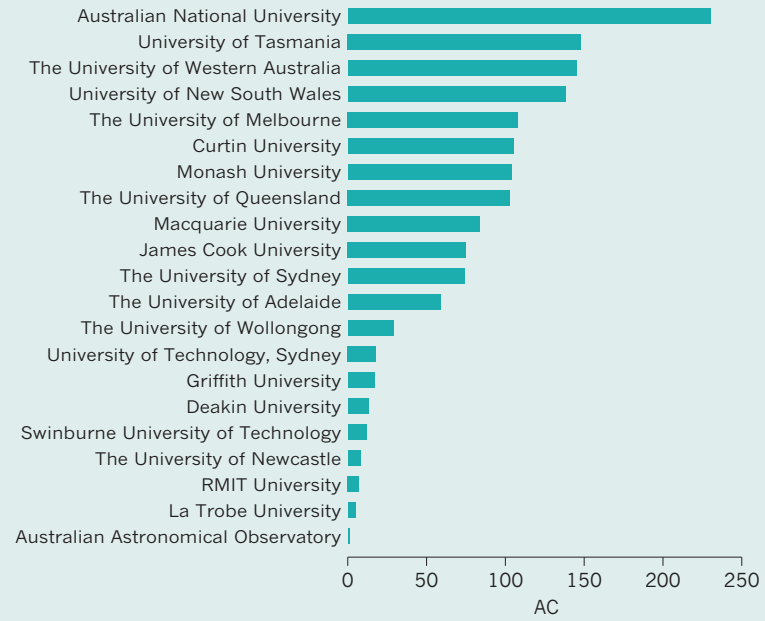

\section{$\$ 7.47 m$
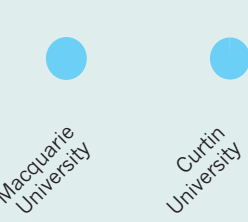

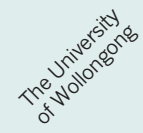

$\$ 10.1 \mathrm{~m}$

$\$ 9.7 m$

$\$ 8.59 m$
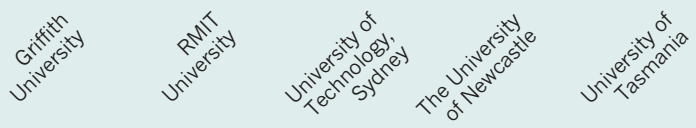

$\$ 5.25 m$

$\$ 3.72 \mathrm{~m}$

$\$ 3.19 m$
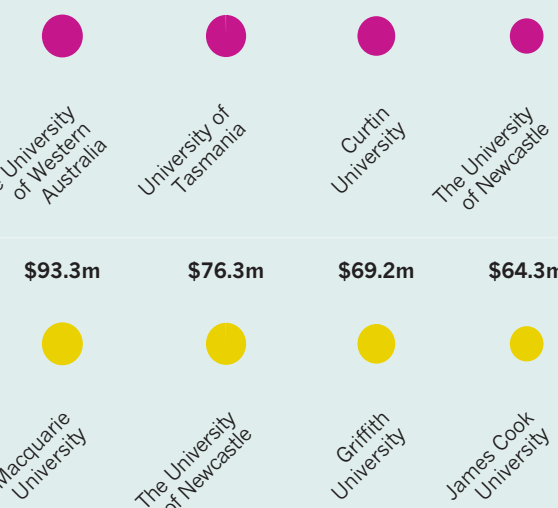

$\$ 76.3 m$

$\$ 69.2 \mathrm{~m}$

$\$ 64.3 \mathrm{~m}$
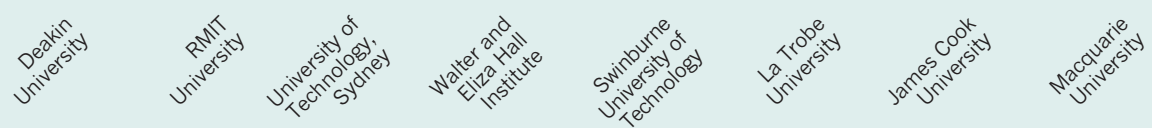

$\$ 42.6 m$

$\$ 20.07 m$
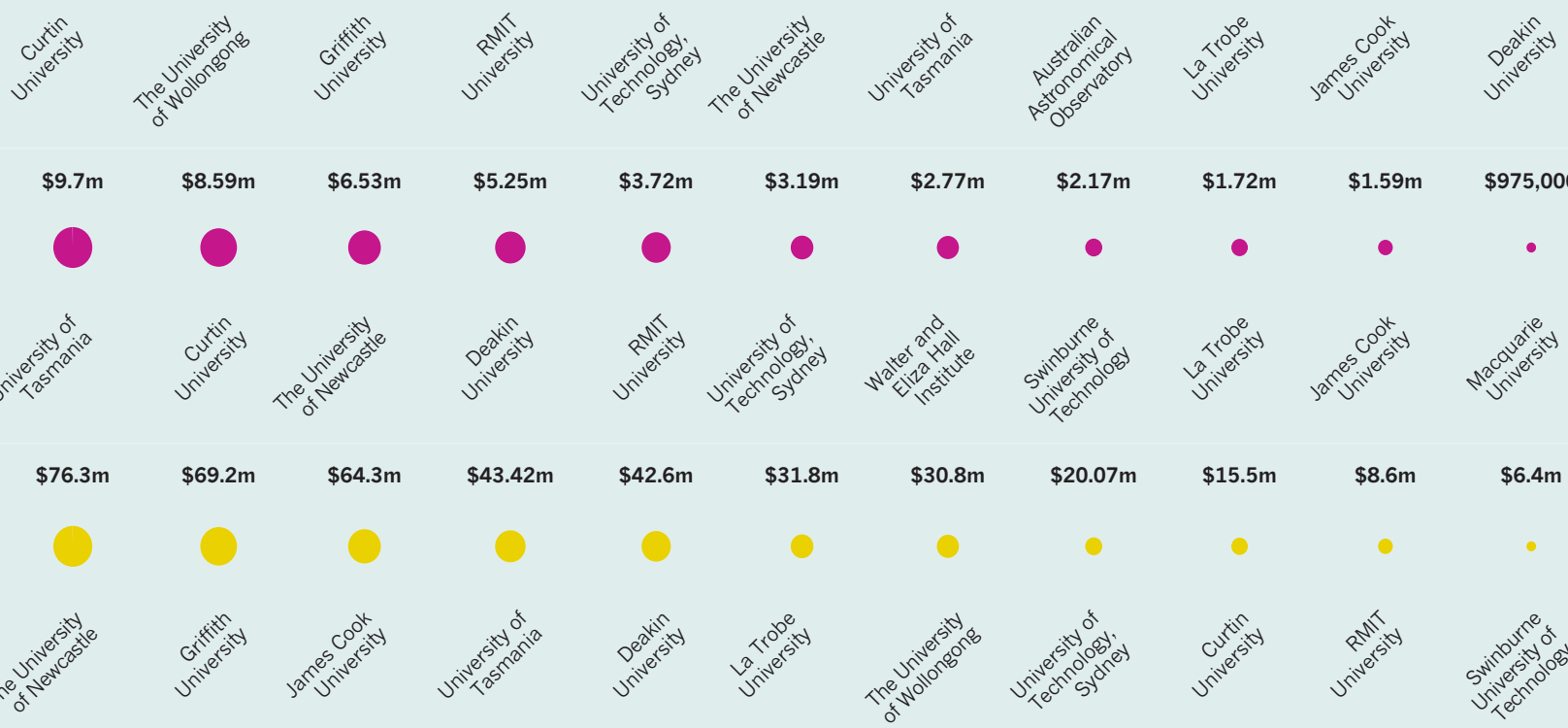

$\$ 17.3 \mathrm{~m}$

$\$ 13.9 m$

$\$ 10.5 \mathrm{~m}$

$\$ 6.72 m$

$\$ 4.81 m$

$\$ 4.3 m$

$\$ 3.97 m$

$\$ 2.67 m$

$\$ 1.7 m$

$\$ 963,000$

$\$ 330,000$

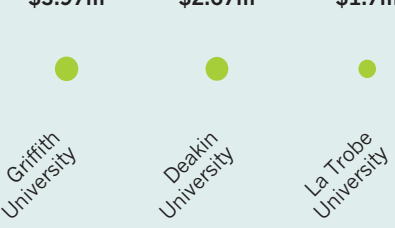

$\$ 210,000$

$\$ 975,000$ 


\section{INVESTING IN SCIENCE}

Australia's top research institutions in the index, excluding CSIRO, are ranked by their contribution to subject areas (grey bars) between 2012 and 2015. Dividing a university's contribution to the index by the amount of research funding it received between 2011 and 2014 indicates, in normalized terms, how it has translated funding into output in the index's high-quality journals (orange bars). The contribution of institutions to journals in the index can be measured by fractional count (FC) or weighted fractional count (WFC). WFC accounts for the large number of astronomy articles in the index, and is used when referring to physical sciences output. It is also a fairer measure of an institution's total contribution to high-quality science (see Total output).

\section{PHYSICAL SCIENCES}

Australian National University University of New South Wales

The University of Melbourne The University of Sydney Monash University

The University of Queensland The University of Western Australia Swinburne University of Technology

The University of Wollongong RMIT University

Macquarie University

The University of Adelaide Griffith University

University of Technology, Sydney Curtin University

Australian Astronomical Observatory

The University of Newcastle University of Tasmania La Trobe University Deakin University James Cook University

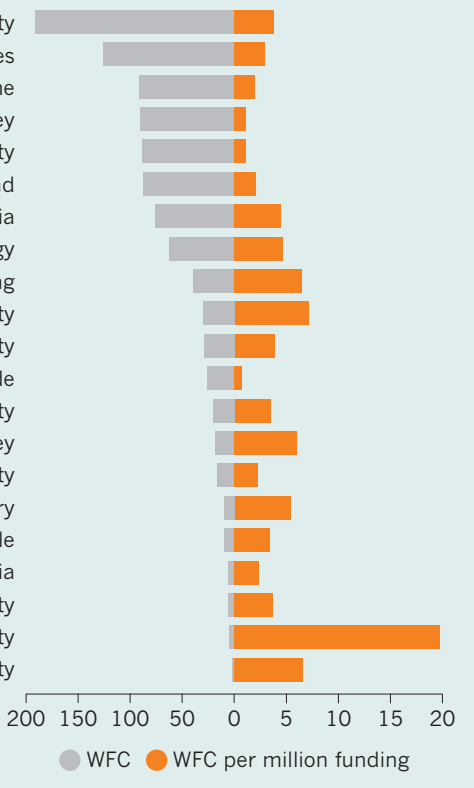

\section{LIFE SCIENCES}

The University of Queensland The University of Melbourne Monash University

The University of Sydney University of New South Wales Australian National University Walter and Eliza Hall Institute The University of Western Australia James Cook University The University of Adelaide Macquarie University University of Tasmania Deakin University La Trobe University Griffith University The University of Newcastle The University of Wollongong University of Technology, Sydney RMIT University Curtin University Swinburne University of Technology

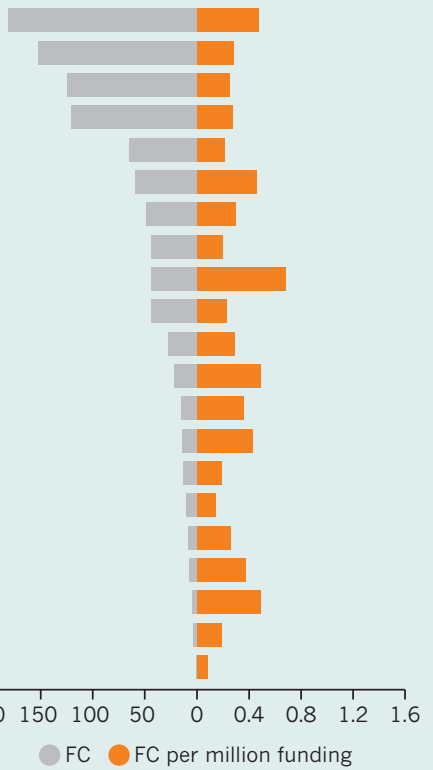

\section{CHEMISTRY}

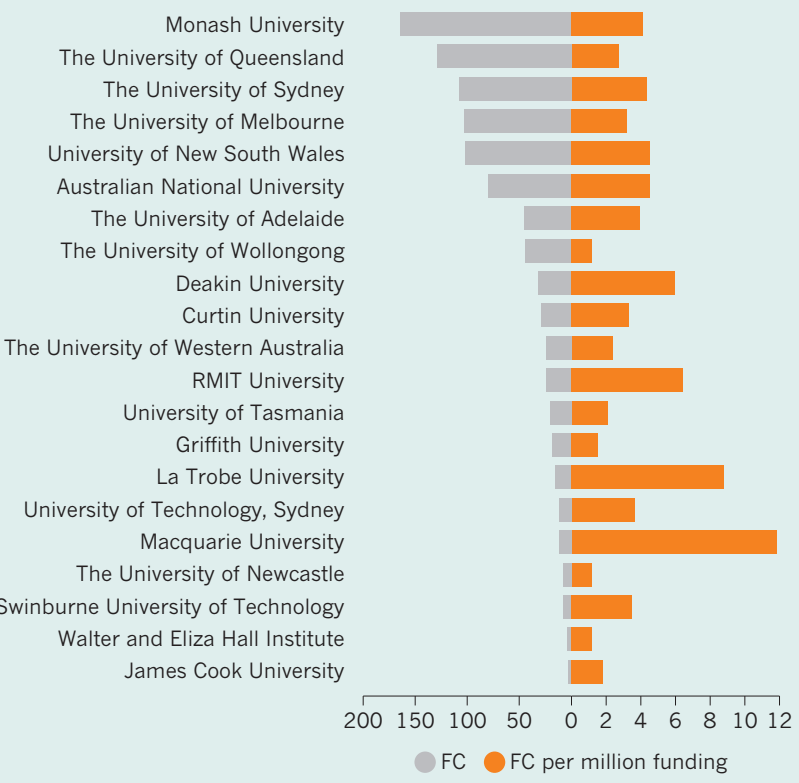

\section{EARTH AND ENVIRONMENTAL SCIENCES}

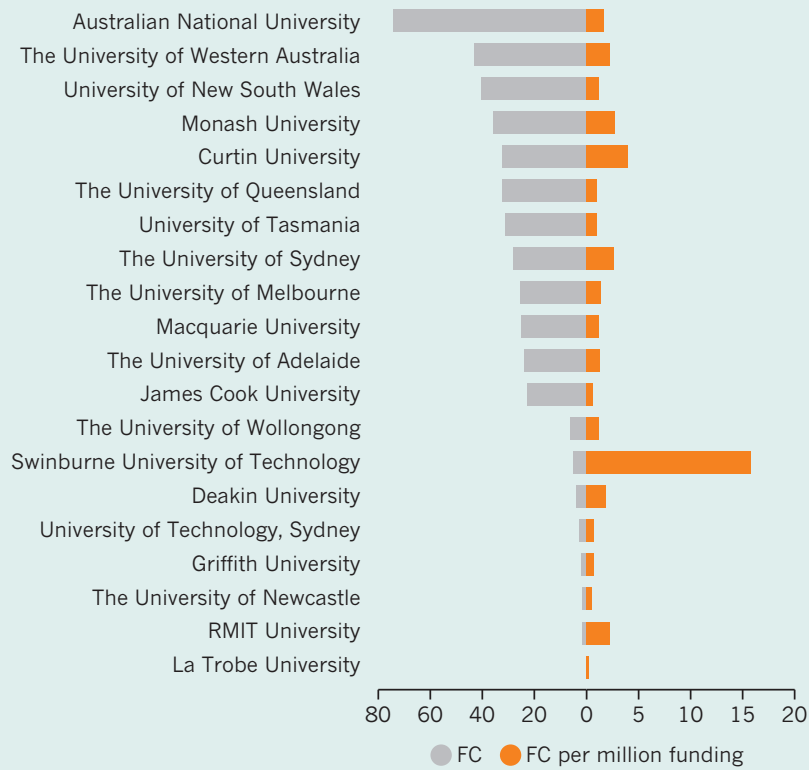

\section{THE FINE PRINT}

Funding data refers to competitive grants, predominantly awarded by the National Health and Medical Research Council (NHMRC) or the Australian Research Council (ARC). Funding data from several smaller medical research charities is also included in the life sciences section. Funding data was obtained by Digital Science' ÜberResearch (see page S77), classified by 'Field of Research'. FoR categories were grouped into the four broad fields in the index. While FoRs align with index fields, a portion of the funding will have been used to fund research published in journals not included in the index. Nevertheless, the above charts give an indication of how effective funding has been in supporting the high-quality research in journals included in the index.

\author{
ONATURE.COM \\ Read more analysis \\ and commentary \\ online, visit: \\ natureindex.com
}




\section{TOTAL OUTPUT}

The total output and subject contributions

of Australian universities to the index,

by WFC, over four years between

2012 and 2015.
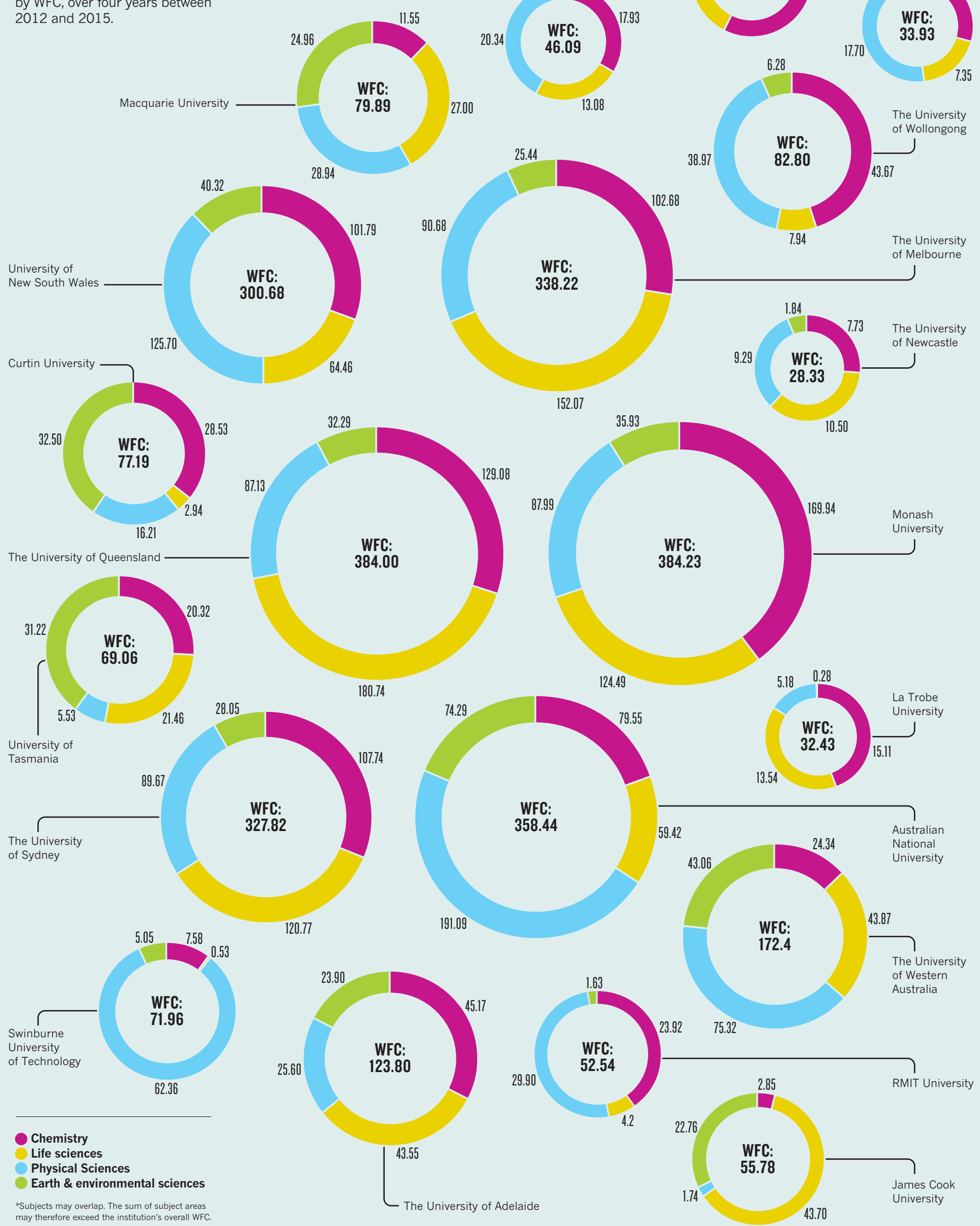

The University of Queensland

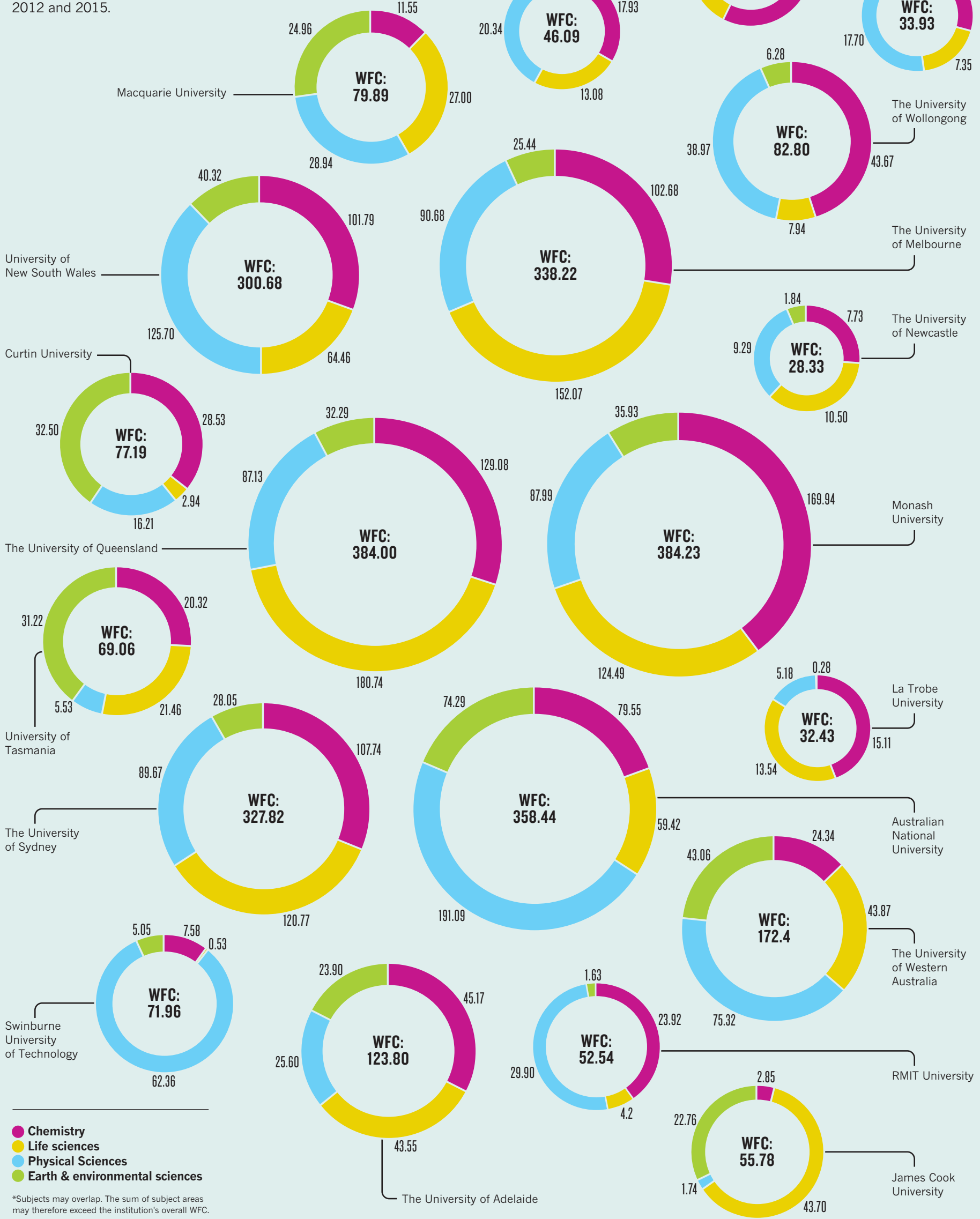

90.68

34

4.14

$89\left\lceil\begin{array}{c}\text { Deakin } \\ \text { Universit }\end{array}\right.$

University of

Sydney 